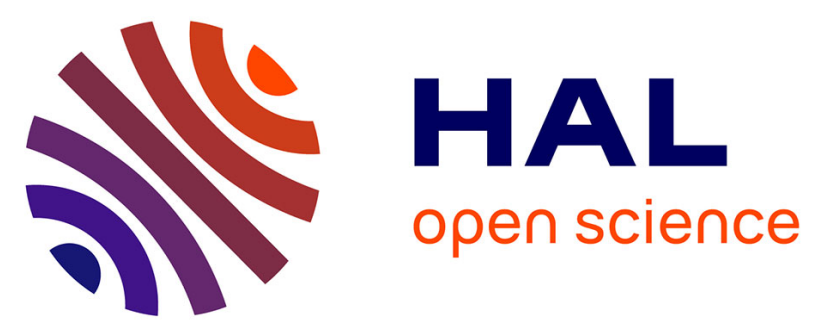

\title{
Comment on "Towards Direct-Gap Silicon Phases by the Inverse Band Structure Design Approach"
}

\author{
M. Amsler, J. A. Flores-Livas, Silvana Botti, Miguel Alexandre Lopes
}

Marques, S. Goedecker

\section{- To cite this version:}

M. Amsler, J. A. Flores-Livas, Silvana Botti, Miguel Alexandre Lopes Marques, S. Goedecker. Comment on "Towards Direct-Gap Silicon Phases by the Inverse Band Structure Design Approach". Physical Review Letters, 2014, 112, pp.199801. 10.1103/PhysRevLett.112.199801 . hal-02313481

\section{HAL Id: hal-02313481 \\ https://univ-lyon1.hal.science/hal-02313481}

Submitted on 16 Feb 2021

HAL is a multi-disciplinary open access archive for the deposit and dissemination of scientific research documents, whether they are published or not. The documents may come from teaching and research institutions in France or abroad, or from public or private research centers.
L'archive ouverte pluridisciplinaire HAL, est destinée au dépôt et à la diffusion de documents scientifiques de niveau recherche, publiés ou non, émanant des établissements d'enseignement et de recherche français ou étrangers, des laboratoires publics ou privés. 


\section{Comment on "Towards Direct-Gap Silicon Phases by the Inverse Band Structure Design Approach"}

In the Letter of Xiang et al. [1], a novel, metastable cubic silicon phase $\mathrm{Si}_{20}$-T was theoretically predicted by the modified particle swarm optimization method CALYPSO [2]. The optical absorption of this phase was computed and compared to that of diamond silicon. $\mathrm{Si}_{20}$-T exhibits a quasidirect gap of $1.55 \mathrm{eV}$ and has a stronger absorption in the visible compared to diamond silicon, which makes it a candidate as a solar energy absorber. However, we have strong reasons to believe that this phase cannot be experimentally synthesized via strong compression or decompression or through molecular encapsulation as proposed by the authors [3].

According to our density functional theory calculations with the Perdew-Burke-Ernzerhof functional, and in agreement with the data reported in Ref. [1], the energy differences at ambient conditions of $\mathrm{Si}_{20}$-T with respect to diamond silicon and to the type II silicon clathrate are 286 and $233 \mathrm{meV} / \mathrm{Si}$, respectively. In fact, Botti et al. [4] predicted a plethora of energetically much more favorable silicon polymorphs, some of which are equally well suited for photovoltaic applications, by employing the minima hopping method [5,6]. In view of that, even in the unlikely case that $\mathrm{Si}_{20}$-T could be synthesized, its stability is highly questionable since it would quickly and highly exothermically decay to some more favorable metastructure, such as those of Ref. [4].

Furthermore, the configurational density of states increases with energy and essentially explodes [7] when amorphous silicon becomes accessible at roughly $290 \mathrm{meV} / \mathrm{Si}$ above silicon diamond [8]. A huge number of structures therefore compete thermodynamically with $\mathrm{Si}_{20}$ - $\mathrm{T}$ such that a crystallization in this phase is very unlikely. To address the above issues, Botti et al. [4] systematically rejected all phases with higher energies than $150 \mathrm{meV} / \mathrm{Si}$ above diamond silicon.

Although compression or expansion of silicon is a valid and promising approach to synthesize novel silicon polymorphs, we are convinced that this approach is not applicable to obtain $\mathrm{Si}_{20}$-T. Xiang et al. [1] conclude that $\mathrm{Si}_{20}-\mathrm{T}$ can be synthesized at cell volumes below $15.6 \AA^{3} / \mathrm{Si}$ or above $37.0 \AA^{3} / \mathrm{Si}$ by boldly comparing its energy/atom curve as a function of volume/atom with respect to diamond silicon alone, ignoring all other lowerenergy metastable polymorphs. This complete neglect of the complex phase diagram of silicon, which undergoes several phase transitions as a function of pressure, is the origin of their erroneous conclusions. The energies of the various silicon phases as a function of atomic volume are shown in Fig. 1. With the full phase diagram in mind, we can clearly see that the $\beta$-tin phase is by far energetically

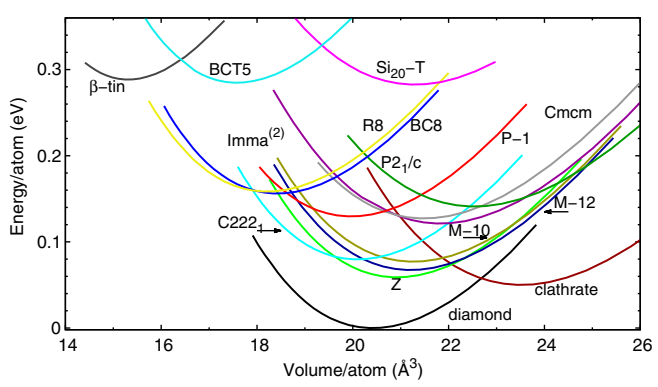

FIG. 1 (color online). Energy/atom as function of volume/atom for the structures in Ref. [4], together with $\mathrm{Si}_{20}$-T.

favored over $\mathrm{Si}_{20}$-T at $16 \AA^{3} / \mathrm{Si}(170 \mathrm{meV} / \mathrm{Si})$, while silicon clathrates are favored in the high volume range (156 meV/Si at $37.0 \AA^{3} / \mathrm{Si}$ ). Note that at this high volume, which corresponds to a negative pressure of $-1.8 \mathrm{GPa}$, our calculations show that $\mathrm{Si}_{20}$-T silicon is dynamically unstable, making it therefore irrelevant to propose the synthesis beyond $37.0 \AA^{3} / \mathrm{Si}$.

Xiang et al. [1] also proposed molecular encapsulation to synthesize $\mathrm{Si}_{20}$-T with intercalated $\mathrm{CH}_{4}$. Again, the authors neglected the energetically more favorable silicon clathrates in their comparison. By inserting $\mathrm{CH}_{4}$ in the clathrate's polyhedra the cell volume expands by merely $1.6 \%$, compared to $8.3 \%$ volume expansion in $\mathrm{Si}_{20}-\mathrm{T}$, resulting in a significantly stronger strained structure. Therefore it is not surprising that, according to our calculations, the clathrate with encapsulated $\mathrm{CH}_{4}$ is favored by $458 \mathrm{meV} / \mathrm{Si}$.

In conclusion, optimizing a single physical property alone when designing novel functional materials is by no means sufficient to predict promising structures, but a rigorous study of the thermodynamic stability is essential when evaluating their synthesizablity.

M. Amsler, ${ }^{1}$ J. A. Flores-Livas, ${ }^{2}$ S. Botti, ${ }^{3}$

M. A. L. Marques ${ }^{3}$ and S. Goedecker,

${ }^{1}$ Department of Physics

Universität Basel, Klingelbergstrasse 82, 4056 Basel

Switzerland

${ }^{2}$ Max-Planck Institut für Mikrostrukturphysik

Weinberg 2, D-06120 Halle, Germany

${ }^{3}$ Institut Lumière Matière and ETSF, UMR5306

Université Lyon 1-CNRS, Université de Lyon

F-69622 Villeurbanne Cedex, France

Received 1 August 2013; published 13 May 2014

DOI: 10.1103/PhysRevLett.112.199801

PACS numbers: 88.40.jj, 42.79.Ek, 71.20.-b, 78.20.Ci

*Stefan.Goedecker@unibas.ch

[1] H. J. Xiang, B. Huang, E. Kan, S.-H. Wei, and X. G. Gong, Phys. Rev. Lett. 110, 118702 (2013).

[2] Y. Wang, J. Lv, L. Zhu, and Y. Ma, Comput. Phys. Commun. 183, 2063 (2012).

[3] Supplemental Material at http://link.aps.org/supplemental/10 .1103/PhysRevLett.110.118702. 
[4] S. Botti, J. A. Flores-Livas, M. Amsler, S. Goedecker, and M. A. L. Marques, Phys. Rev. B 86, 121204 (2012).

[5] S. Goedecker, J. Chem. Phys. 120, 9911 (2004).

[6] M. Amsler and S. Goedecker, J. Chem. Phys. 133, 224104 (2010).
[7] S. A. Ghasemi, M. Amsler, R. G. Hennig, S. Roy, S. Goedecker, T. J. Lenosky, C. J. Umrigar, L. Genovese, T. Morishita, and K. Nishio, Phys. Rev. B 81, 214107 (2010).

[8] S. C. Jung and Y.-K. Han, Electrochim. Acta 62, 73 (2012). 